\title{
Relevance Of Prior Academic Qualifications To Predicting The Academic Achievement Of Undergraduate Students: An Analysis Of Law Enrollees At Makerere University
}

Robert Wamala, Makerere University, Uganda

\begin{abstract}
Students who have excelled academically in the past are regarded as having a greater chance of performing successfully in subsequent examinations. However, this argument is being questioned with regard to enrollees onto the Bachelor of Laws at the School of Law of Makerere University in Uganda. This study sought to obtain an understanding of this issue using administrative data of 568 Bachelor's of Law graduates of Makerere University during the period 2010-2012. A combined weighted score for the enrollees granted on admission to the program and their Cumulative Grade Point Average (CGPA) on graduation were adopted as measures of their prior academic qualifications and academic achievement, respectively. An assessment of the enrollees' academic achievement is made using summary statistics. The bearing of prior academic qualifications on the academic achievement was investigated using a robust regression, controlling for student's characteristics, gender, nationality, and year of enrollment. A median CGPA of 3.16 in the results points to a "lower second" class degree obtained by a considerable number of graduates in the program. In the multivariate assessment, high scores on entry to the program were significantly associated with high academic achievement $(p<0.01)$. These findings confirm enrollees' prior academic qualifications as: 1) a predictor of academic achievement on the program and 2) thus, an indisputable measure for assessing the competence of candidates suitable for admission to the program.
\end{abstract}

Keywords: Academic Achievement; Undergraduate Students; Prior Academic Qualifications

\section{INTRODUCTION}<smiles>CC1CCCCC1</smiles>

ganda follows a 7-4-2-3+ model of education-seven years of primary, four years of lower secondary (Ordinary Level), two years of upper secondary (Advanced Level), and three-to-five years of tertiary education. The major immediate outcomes of the O-Level and A-Level stages are the Uganda Certificate of Education (UCE) and Uganda Advanced Certificate of Education (UACE). Thus, the path to a Bachelor of Law degree in the country is typically via the Advanced (A-Level) level of secondary education. As such, prior to 2012, admission to the Bachelor of Law program at Makerere University has been based on the prior performance of candidates reflected by their UCE and UACE results. However, candidates for the program in the 2012 enrollment cohort were subjected to an entry examination-candidates for the program in subsequent periods (2013 and beyond) will have to go through the same process to gain admission to the program, unless otherwise indicated. Eligibility to sit for the examination, as stipulated by the University (Makerere University, 2012), requires:

1. UCE with at least five passes and UACE with a minimum of 14 or 15 points in any A-Level combination for males and females, respectively

2. Diploma holders applying for the program must possess at-least a second class or Credit Diploma in any discipline from a recognized university.

3. Mature candidates for the program must have passed the mature age entry examination to the program.

2013 The Clute Institute http://www.cluteinstitute.com/ 
4. Degree holders must be graduates in any discipline from a recognized university in the country.

5. Persons with disabilities and talented sportsmen/sportswomen who intend to gain admission to the program should possess UCE with a minimum of five passes and two principle Advanced Level (UACE) passes.

Although prior academic qualifications (UCE and UACE) are a prerequisite for eligibility to sit for the entry examination, admission to the program among enrollees in the 2012 cohort and onward will solely be based on the outcome of the examination. In other words, the performance of candidates in the entry examination is used as the measure of enrollees' academic competence. Having an entry examination, to a large extent, diminishes the significance of enrollees' prior academic qualifications. In other words, it questions the argument that students who have excelled academically in the past have a greater chance of successful performance (e.g., Alfan \& Othman, 2005; Bariez, 2002; Duff, 2004; Kyoshaba, 2009; Wamala \& Buyinza, 2013; Wamala, Omala, \& Kakumba, 2012). Equivalently, it questions the reliability of a candidate's prior academic qualifications as a measure of competence for admission to the program. Although Bariez (2002), Wamala and Buyinza (2013), and Wamala et al.'s (2012) argument of successful performance among students who have excelled academically in the past may be true to a certain extent, this issue is debatable regarding Bachelor of Law enrollees at the School of Law of Makerere University in Uganda. Up to 2012, enrollees on the program were admitted because of impressive grades in their prior academic qualifications-however, the low performance of many of these enrollees, after a stipulated period of four years of Bachelors studies, has raised concern from the University faculty and the public regarding the grounding involved in the prior academic qualifications of the students, among other issues. Consequently, the University Council, on recommendation by the Senate, considered introducing a pre-entry examination to the Bachelor of Laws program (Makerere University, 2011). The examination is to be adopted as a measure of determining competence of candidates suitable for admission to the program among enrollees in the 2012 cohort and onward. In a March 2012 letter to the Minister of Education and Sports (MoES), the University's decision to institute the examination was based on a mismatch suggested between prior academic grades and performance of enrollees in the program. High failure rates on the program were attributed to poor compression, communication and analytical skills as well as a shallow grounding in legal principles (Makerere University, 2012, p.1).

The shift in entry requirements to the program has led to the University having legal battles to deal with, as reported in The Observer newspaper article on the subject (Talemwa, Wanyenze, Ninsiima, Kamukama, Mwesigwa, Kimbowa \& Baranga, 2013). Challenging the University's pre-entry examination requirement, Talemawa et al. (2013) wrote:

A group of lawyers led by Ntenjeru South Member of Parliament, Patrick Nsanja, filed a case in the High Court challenging the university's new policy of subjecting prospective Law students to "an examination whose mode of setting, grading and marking is unknown." They argue that the university is in breach of Article 21 of the Constitution and that many people that qualify for the law programme would be left out.

In response to the challenge from the legal fraternity regarding the University's shift in entry criteria for the program, the institution has argued that it has the right to change any requirements at any time or to set additional conditions for admission provided that they are approved by the Senate and the University Council (Talemwa et al., 2013). However, for a "research-led-University", as the institution considers itself to be (Makerere, 2012), the answer to this predicament is not determined by a court of law; rather, an assessment of the issue, found through scientifically proven research, would certainly provide a satisfactory answer regarding whether or not the university was justified in its decision to introduce an entry examination for admission to the program. Regardless of the true state of affairs leading to the shift in entry requirements, the relevance of prior academic qualifications to predicting the academic achievement of enrollees in the program remains debatable. Therefore, this study sought to provide an insight into this issue of contention. The analysis controls for variations in the characteristics of enrollees to account for the possible causes of differentials in their prior qualifications and subsequent academic achievement in the program.

\section{DATA AND METHODS}

The investigations are based on administrative data on enrollees for the Bachelor of Law program in the 2005-2007 cohorts of the School of Law of Makerere University in Uganda. However, only enrollees who 
graduated with their bachelor's degree by December 2012 were considered in the analysis-the data comprised a total of 568 graduates. This figure excludes graduates in the specified enrollment cohorts who were admitted to the program under the Diploma and Mature student schemes. Each student graduating CGPA is adopted as a measure of academic achievement. The combined weighted score of the enrollees on admission to the program was adopted as a measure of their prior academic qualifications. The score is based on the enrollees' performances in their Advanced (UACE) and Ordinary (UCE) levels of secondary education. The A-Level weights are obtained by multiplying each subject grade point by the relevant weighting factor and adding up for all the subjects taken and passed. A similar procedure is followed for obtaining weights for the O-Level stage. According to the 2013-2014 MoES weighting criteria (UNEB, 2012), all subjects studied at A-level are grouped into four categories and weighted as either Essential (weight factor of three), Relevant (weight of two), Desirable (weighted one), or Others (weight of 0.5). For O-Level grades, distinctions 1 and 2 carry a weight of 0.3 , while credits 3-6 carry 0.2 ; 'Passes' 7 and 8 carry 0.1 and a 'Failure' carries 0.0 weight. The best candidate for the program is the one with the highest combined weight.

The analysis was performed in three stages:

1. The academic achievement of enrollees in their Bachelor's degree (CGPA) and student characteristics (gender, nationality, year of enrollment, private-government sponsorship type, and prior academic qualifications) were presented using summary statistics and frequency distributions.

2. A variation in the academic achievement of enrollees by student characteristics was investigated using the Kruskal-Wallis test - a non-parametric test.

3. The association between prior academic qualifications and the academic achievement of the enrollees was modeled using a robust regression, controlling for student characteristics. The choice of the robust regression, adopted for the multivariate analysis, was based on the fact that the ordinary least squares (OLS), in a Multiple Linear Regression (MLR), may not be an appropriate method for obtaining estimates because the data may violate some of its fundamental assumptions; that is, outliers, non-normality, influential points, and/or missing data, among others (Ho \& Naugher, 2000). However, the robust regression is able to cope with or detect outlying observations in the direction of both the dependent and explanatory variables (Berk, 1990; Birkes \& Dodge, 1993; Alma, 2011). Otherwise, the estimates and/or results found using the MLR could be misleading if the data do not satisfy some of the regression assumptions of an OLS model.

During the second and third stages of the analysis, associations between the variables were established at $5 \%(\mathrm{p}<0.05)$ and $1 \%(\mathrm{p}<0.01)$ levels of significance, unless otherwise stated. The subsequent sections present an analysis of the data based on the aforementioned approaches.

\section{RESULTS}

The results relate to 568 Bachelor of Law graduates of Makerere University, characterized as predominantly Ugandan by nationality $(95.4 \%)$, slightly over five in every nine enrollees were females $(56.6 \%)$, and on a private sponsorship scheme $(55.9 \%)$. No major variations were noted with regard to the year of enrollment in the program $-36.4 \%$ of enrollees were in the 2005 cohort, $35.9 \%$ in 2006, and the rest were in the 2007 cohort.

\section{Academic Achievement Of Enrollees}

Table 1 presents summary statistics of the academic achievement of the enrollees based on their CGPA during graduation.

Table 1: Summary Statistics Of The Academic Achievement Of Enrollees

\begin{tabular}{|l|c|c|c|c|}
\hline \multicolumn{1}{|c|}{ Enrollment Cohort } & N & Min & Max & Median \\
\hline 2005 & 207 & 2.39 & 4.30 & 3.16 \\
\hline 2006 & 204 & 2.33 & 4.21 & 3.14 \\
\hline 2007 & 157 & 2.68 & 3.89 & 3.19 \\
\hline Total & $\mathbf{5 6 8}$ & $\mathbf{2 . 3 0}$ & $\mathbf{4 . 3 0}$ & $\mathbf{3 . 1 6}$ \\
\hline
\end{tabular}

Note. The graduating CGPA is adopted as a measure of academic achievement 
Overall, the median CGPA of the graduates in the program is 3.16 (range of 2.30-4.30). This figure implies that a "lower second" class of degree was obtained by a considerable number of graduates in the program. The findings point to low academic achievement amongst the graduates. The CGPA estimates obtained for graduates in the various enrollment cohorts do not indicate any differences with regard to the academic achievement of the students in the program.

\section{Characteristics Of Enrollees And Their Academic Achievement}

This section presents an analysis of academic achievement in relation to the enrollees' prior academic qualifications and characteristics. The analysis is done in two stages: 1) A bivariate assessment of academic achievement by enrollees' characteristics is conducted to provide an insight into the nature of the associations (if any) between the variables and 2) Following the outcomes of the bivariate analysis, a multivariate analysis of enrollees' achievement is conducted to determine the net-impact of the explanatory variables. As stated earlier, the multivariate stage of analysis controls for variations in the characteristics of the enrollees. In other words, the multivariate assessment investigates the bearing of prior academic qualifications on academic achievement, while controlling for the characteristics of the enrollees on the program.

To this end, Table 2 presents a bivariate assessment of students' academic achievement by their characteristics and Table 3 presents a multivariate assessment of the bearing of prior academic qualifications on academic achievement, while controlling for the students' characteristics.

Table 2: Bivariate Assessment Of The Academic Achievement By Characteristics Of Enrollees

\begin{tabular}{|c|c|c|c|}
\hline Student Characteristics & $\mathbf{N}^{\mathbf{a}}$ & Rank Sum ${ }^{b}$ & Average Rank \\
\hline \multicolumn{4}{|l|}{ Gender } \\
\hline Female & 365 & 106404.0 & 291.5 \\
\hline Male & 203 & 55192.0 & 271.8 \\
\hline \multicolumn{4}{|l|}{$\chi^{2}=1.86, \mathrm{p}=0.1718$} \\
\hline \multicolumn{4}{|l|}{ Sponsorship Status } \\
\hline Government & 239 & 85641.0 & 358.3 \\
\hline Private (Evening) & 280 & 62087.0 & 221.7 \\
\hline Private (Day) & 49 & 13868.0 & 283.0 \\
\hline \multicolumn{4}{|l|}{$\chi^{2}=89.32, \mathrm{p}=0.0001$} \\
\hline \multicolumn{4}{|l|}{ Nationality } \\
\hline Ugandan & 542 & 154431.5 & 284.9 \\
\hline Non-Ugandan & 26 & 7164.5 & 275.5 \\
\hline \multicolumn{4}{|l|}{$\chi^{2}=0.34, \mathrm{p}=0.5584$} \\
\hline \multicolumn{4}{|l|}{ Year of Enrollment } \\
\hline 2005 & 207 & 59923.5 & 289.4 \\
\hline 2006 & 204 & 55605.0 & 272.5 \\
\hline 2007 & 157 & 46067.5 & 293.4 \\
\hline
\end{tabular}

Note. Analysis is based on all 568 Bachelor of Law graduates in the period 2010-2012 with the exception of enrollees on

"Mature Entry" and those on the Diploma scheme.

${ }^{\text {a }}$ Sum of ranks generated in each of the categories following the Kruskal-Wallis Test 
Table 3: Regression Estimates of Academic Achievement by Prior academic qualification and Enrollees' Characteristics

\begin{tabular}{|c|c|c|c|}
\hline Independent Variables & Coef. $^{\text {a }}$ & Std. Err & p-value \\
\hline \multicolumn{4}{|l|}{ Gender } \\
\hline Female $^{\dagger}$ & . & . & . \\
\hline Male & -0.007 & 0.026 & 0.788 \\
\hline \multicolumn{4}{|l|}{ Nationality } \\
\hline Non-Ugandan $^{\dagger}$ & . & . & . \\
\hline Ugandan & -0.062 & 0.046 & 0.183 \\
\hline \multicolumn{4}{|l|}{ Year of Enrollment } \\
\hline \multicolumn{4}{|l|}{$2005^{\dagger}$} \\
\hline 2006 & -0.116 & 0.031 & 0.000 \\
\hline 2007 & -0.050 & 0.030 & 0.094 \\
\hline \multicolumn{4}{|l|}{ Prior Qualifications } \\
\hline WT(3) ${ }^{\mathbf{c}}$ & 0.006 & 0.005 & 0.000 \\
\hline Cons. & 3.280 & 0.048 & 0.000 \\
\hline
\end{tabular}

Note. Estimates were obtained using a robust regression; $N=568, F=26.43, p<0.01$

Represents the reference categories that were adopted

${ }^{\text {a }}$ Coefficients

${ }^{\mathrm{c}}$ Represents the combined weighted score adopted on admission, modeled by a fractional polynomial of power three

The following conclusions were reached from the preliminary analysis using the MLR in an OLS:

1. The homoscedasticity assumption was violated, demonstrated by the Cook-Weisberg test $\left(\chi^{2}=3.9, \mathrm{p}<0.05\right)$.

2. The assumption of the normality of residuals was supported by a Smirnov-Kolmogorov test $(\mathrm{p}>0.05)$.

3. In an assessment of the existence of outliers and/or influential points conducted using standardized residuals, no values were in excess of 3.5 or -3.5 (absolute values of the residuals were less than 3.5 ); thus, no outliers were observed in the data.

Therefore, a robust regression with Huber/White/Sandwich variance-covariance estimators was adopted in the multivariate analysis to correct for the homoscedasticity assumption. Nevertheless, the fact that the combined weighted scores on admission to the program are highest among government-sponsored students, followed by dayprivate students and then those in evening programs, means that the variable cannot be analyzed alongside the individual combined weights for each of the enrollees on the program. In other words, both the type of entry to the scheme (government vs. private) and the weighted scores of individuals can be adopted as a measure of enrollees' prior academic qualifications. Thus, academic achievement was modeled on individual combined weighted scores and the characteristics of the enrollees. The functional form of the weighted score variable (which is continuous in nature) was determined in the analysis using fractional polynomials - this study did not assume a linear functional form for this variable. A discussion and summary of the findings follow.

From the bivariate assessment in Table 2, no significant associations were established between enrollees' characteristics and academic achievement, with the exception of the type of sponsorship scheme $(\mathrm{p}<0.05)$. The findings suggest no direct relationship between the variables and the academic achievement of students in the program. Although the variables did not vary significantly with academic achievement, incorporating them into the analysis at the multivariate stage was vital to obtaining the net-impact of enrollees' prior academic qualifications.

The multivariate results in Table 3 reveal a significant variation in academic achievement by prior academic qualifications and enrollees' cohort $(\mathrm{p}<0.01)$. These findings can be summarized as follows:

1. The association between the enrollees combined weighted score and academic achievement was non-linear (See Figure 1); the student's graduating CGPA increases with their weighted score on admission to the program.

2. Students in the 2006 enrollment cohort had a lower graduating CGPA compared to those in 2005.

No significant variations in academic achievement were observed by gender or nationality ( $\mathrm{p}>0.05)$.

2013 The Clute Institute http://www.cluteinstitute.com/ 


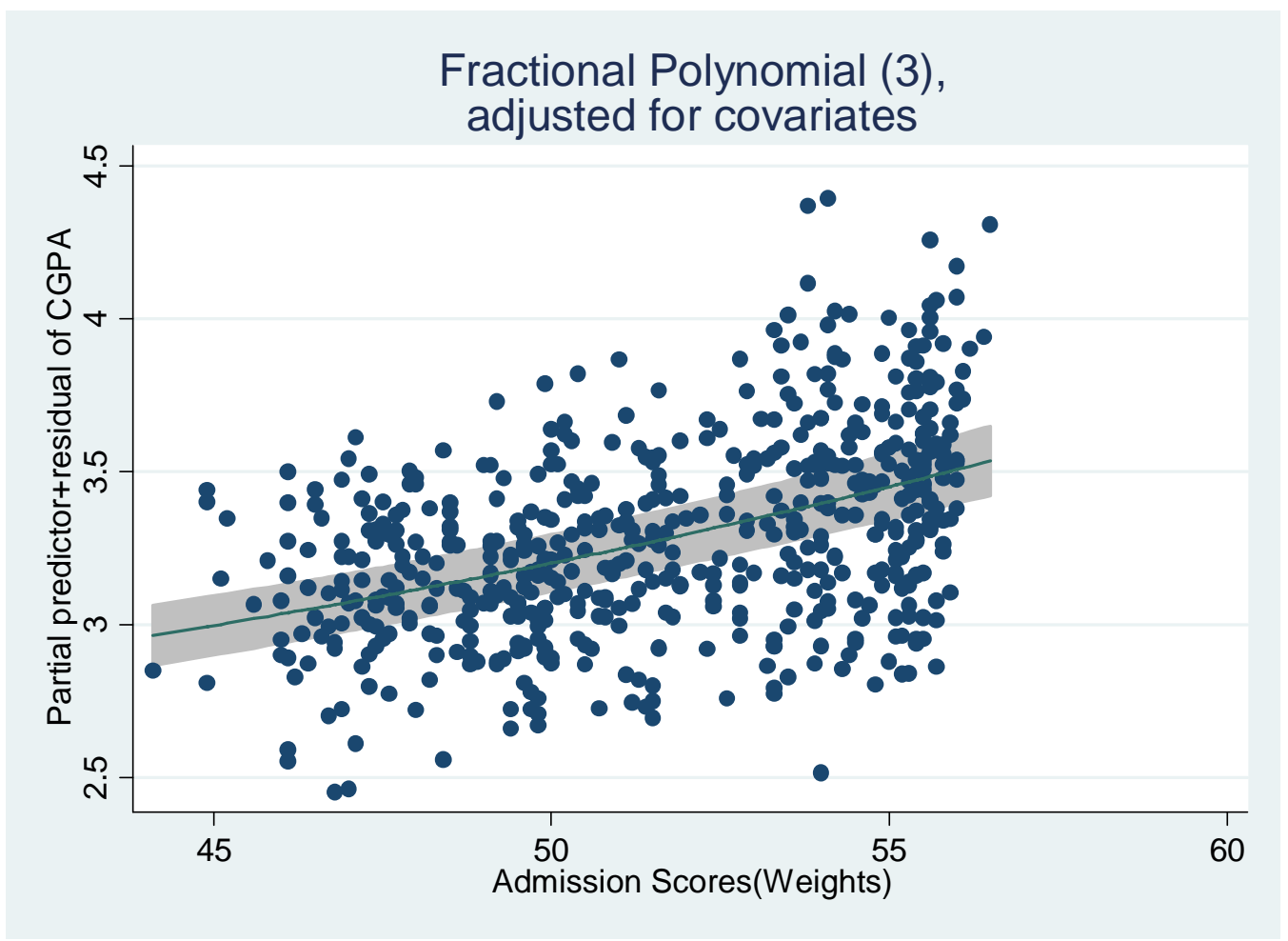

Figure 1: Relationship Between Enrollees' Weighted Score And Their Graduating CGPA

\section{DISCUSSION}

The overall median CGPA (3.16; range of 2.30-4.30) obtained in the results confirms the suggestions of low academic achievement or performance by Makerere University's Bachelor of Law graduates (e.g., Talemawa et al., 2013). Although academic achievement was generally low, it was found to vary significantly $(p<0.05)$ with enrollees' prior academic qualifications, represented by the candidates' combined weighted score adopted by the University on admission to the program. As indicated earlier, the candidates' weighted score represents their academic achievement in the Advanced (UACE) and ordinary (UCE) levels of secondary education. In other words, a higher combined weighted score is associated with higher achievement in prior academic qualifications. In the multivariate assessment, the combined weighted score was positively associated with enrollees' academic achievement in the program $(\mathrm{p}<0.05)$. Therefore, the argument that students who have excelled academically in the past have a greater chance of successful performance (e.g., Bariez, 2002; Duff, 2004; Wamala et al., 2012; Wamala \& Buyinza, 2013) is strongly supported. The fact that prior academic qualifications were significantly associated with the academic achievement of enrollees in the program implies that 1) the outcomes of O-Level (UCE) and/or A-Level (UACE) secondary education can be adopted as measures of competence in undertaking undergraduate studies at the university and 2) an argument of a match between UNEB grades and performance of enrollees on the program is highly supported.

A consensus with regard to the bearing of prior academic qualifications on enrollees' academic achievement is not only reached across graduate enrollees (e.g., Bariez, 2002; Navarro, Vitamog, Tierra, \& Gonzalez, 2011; Wamala et al., 2012) and undergraduate enrollees (e.g., Hoskins, Newstead, \& Dennis, 1997; Duff, 2004; Alfan, \& Othman, 2005; Halpern, 2007; Kyoshaba, 2009), but also across disciplines. Duff's (2004) and Alfan and Othman's (2005) studies support this association for accounting and business economics undergraduate students; the findings in this study arrive at a similar conclusion based on Law enrollees. Halpern's (2007) and Hoskins, Newstead, and Dennis' (1997) studies come to the same conclusions based on business management and national statistics modules, respectively. Meanwhile, the fact that these studies were carried out in different regions 
(i.e., Scotland, Norway, UK, Malaysia, and Uganda) suggests that the association applies across countries. Therefore, the findings point to enrollees' prior academic qualifications as being a measure determining the competence of candidates and their suitability for admission to graduate programs.

In light of the fact that the type of sponsorship scheme (mode of study) can be adopted as a measure of the enrollees' prior academic qualifications, one could conclude that candidates on government sponsorship schemes, who are admitted because of their impressive grades, will have higher academic achievement in the program. As a matter of fact, the bivariate assessment of this issue supports this hypothesis - that the CGPAs, on graduation, were highest amongst government-sponsored students, followed by private students in the day program, and lowest among those in the evening program. An analysis of the 248 undergraduate students, across disciplines, who obtained first-class degrees in the University's 63rd graduation (Makerere University, 2013) does not show otherwise; the majority of first-class $(67.3 \%)$ degrees were government-sponsored students, followed by private students in the day program $(22.6 \%)$, while the rest were those in the evening program. The combined weighted scores of enrollees on admission to the program follow a similar pattern as the performance of graduates in the program, as noted in the results. Thus, the most competent candidates for the program are certainly identified by their prior academic qualifications. These findings point to shortfalls in the teaching and/or learning environment or process as the possible cause of the low performance of the students. A recent Change Management Committee Baseline Survey carried out in the University's academic units (Makerere University, 2012) affirms shortfalls in the teaching and/or learning environment in several academic units at the University. At the School of Law, a student body of 1201, the vast majority being undergraduates (97\%), is rather high based on computer facilities, space available for lectures, as well as number and distribution of teaching staff in the academic unit. The unit has the highest student computer ratio (301:1) among the university's units; it is one of the least performing with regard to space ratio per student. The unit has a relatively low number of senior academic staff $-\mathrm{a}$ total of 30 out of the 50 academic staff $(60 \%)$ at the unit are at the rank of assistant lecturer and below. The situation is worsened by the staffing deficit in the University's academic units. Recent evidence published by The Independent newspaper presents a staff deficit of $49 \%$ according to findings by the office of the auditor general (Asinja, 2012). In light of the staffing deficit in the university's academic units, Mugimu et al.'s (2009) argument of a heavy teaching and supervisory workload for the teaching staff at the university is highly supported.

In light of the shortfalls observed among enrollees in the program with regard to comprehension, communication, analytical and knowledge in legal principles (Makerere University, 2012, p.1), remedies to low performance should be tailored toward addressing these in-competencies. All the same, enhancing competence, in knowledge of legal principles particularly, is a mandate of university rather than secondary education. Thus, it is debatable that the entry examination would be the ideal remedy for dealing with these in-competencies. The relevance of the entry examination in predicting the academic achievement of the enrollees is, however, outside the scope of the study; thus, further investigation is required in order to provide an indisputable conclusion with regard to the subject.

In an investigation of the Graduate Management Admission Test (GMAT) among candidates to the Masters in Business Administration (MBA) of Makerere University, the results show that the entry examination is a predictor of success in the graduate program (Wamala, et al., 2012). However, the outcome of the examination was also noted to be significantly associated with the enrollees' academic achievement at the Bachelor degree level. This evidence diminishes the importance of administering the examination as a measure of determining candidates' competence. Although this assessment was made based on graduate students, it is unlikely that the findings would be different for undergraduate students. Furthermore, an association between the introduction of the GMAT and enhancing the quality of educational outcomes was also not supported. However, the true state of affairs regarding the quality of educational outcomes and whether or not the entry examination should be waived among Bachelor of Law enrollees at the University remains unanswered. This is because the entry criteria was only introduced among enrollees in the 2011 entry cohort - the assessment can only be carried out after three years when the cohort is expected to graduate from the program. Nevertheless, the results regarding the quality of educational outcomes are not expected to vary significantly from the findings established among MBA enrollees at the College of Business and Management Science (CoBAMS) of Makerere University. 


\section{SUMMARY}

In sum, the fact that the pool of applicants in the program (mainly A-Level graduates) has not changed, it is unlikely that better academic outcomes will be obtained by varying the entry criteria because the highly competent candidates in the program are predicted by their prior academic qualifications - represented by their academic achievement in Advanced and Ordinary levels of secondary education - UACE and UCE, respectively. In other words, the relevance of enrollees' prior academic qualifications to predicting their academic achievement on the program is not questionable, despite the generally poor performance of the students noted in the results. Thus, the idea of administering a pre-entry examination is unwarranted since prior academic qualification is a cost-free alternative for determining the competence of candidates suitable for admission to the program. Thus, prior academic qualification is an indisputable measure for determining the competence of candidates suitable for admission to the program.

\section{AUTHOR INFORMATION}

Robert Wamala, Ph.D. School of Statistics and Planning, Makerere University, Uganda. E-mail: rwamala@isae.mak.ac.ug

\section{REFERENCES}

1. Alfan, E., \& Othman, M. N. (2005). Undergraduate students' performance: the case of University of Malaya. Quality Assurance in Education, 13(4), 329-343. doi:10.1108/09684880510626593

2. Asinja, M. H. (2012). Makerere Loses Staff Over Low Pay. The Independent. Retrieved on February 24, 2013 from http://www.independent.co.ug/news/news-analysis/5863-makerere-losing-staff-over-low-pay

3. Bariez, S. E. S. (2002). Analysis of the UNP College of Teacher Education graduates' performance in the Licensure Examination for Teachers (Unpublished master's thesis). University of Northern Philippines, Vigan City, Philippines.

4. Duff, A. (2004). Understanding academic performance and progression of first-year accounting and business economics undergraduates: the role of approaches to learning and prior academic achievement. Accounting Education, 13(4), 409-430. doi:10.1080/0963928042000306800

5. Halpern, N. (2007). The impact of attendance and student characteristics on academic achievement: findings from an undergraduate business management module. Journal of Further and Higher Education, 31(4), 335-349. doi:10.1080/03098770701626017

6. Hoskins, S. L., Newstead, S. E., \& Dennis, I. (1997). Degree Performance as a Function of Age, Gender, Prior Qualifications and Discipline Studied. Assessment \& Evaluation in Higher Education, 22(3), 317-328. doi:10.1080/0260293970220305

7. Kyoshaba Martha (2009). Factors affecting Academic Performance of Undergraduate Students at Uganda Christian University. Dissertation Report. Retrieved from http://news.mak.ac.ug/documents/Makfiles/theses/Kyoshaba\%20Martha.pdf

8. Makerere University (2013). Announcement: Pre-entry Examinations for Admission to the Bachelor of Laws (2012/2013). Retrieved January 10, 2013, from http://mak.ac.ug/about/makerere-today/pre-entryexam-bachelor-laws-20122013-entry

9. $\quad$ Makerere University (2011). Pre-Entry Exams for LL.B Entrants introduced by the School of Law. Press Release. Retrieved January 102013 from http://vc.mak.ac.ug/pressrelease/2011/10/PreEntryExamsforLL.BEntrants.pdf

10. Makerere University (March, 2012). Introduction of Pre-Entry Examination to the Bachelor of Laws [Letter to Minister of Education and Sports].

11. Makerere University (2012). Makerere University Change Management Committee Baseline Survey status report as of 22 December 2012. Kampala: Makerere University.

12. Makerere University (2013, January 22-29). First Class Student's Graduation List. The Makererean, p. 6-8

13. Mugimu, C. B., Nakabugo, M. G., \& Katunguka-Rwakishaya, E. (2007). Exploring the factors affecting staff research output and completion rates of graduate students in Makerere University. Kampala, Uganda: Makerere University. 
14. Talemwa, M., Wanyenze, I., Ninsiima, R., Kamukama, P., Mwesigwa, A., Kimbowa, J., \& Baranga, S. (2013). Makerere Law Exam Results. The Observer. Retrieved from http://www.observer.ug/index.php?option=com_content\&view=article\&id=18885:makerere-law-examresults-

15. Navarro, R.T, Vitamog, A.T., Tierra, R.J.C, \& Gonzalez, D.M.J. (2011). Predictors of Nursing Board Examination performance. JPAIR Multidisciplinary Journal, 6(1), 232-246.

16. Makerere University (2013). Research and Innovations Policy. Retrieved January 10, 2013, from http://policies.mak.ac.ug/old/downloads/MAKERERE_UNIVERSITY_RESEARCH_POLICY.pdf.

17. Wamala, R., Omala, S. K., \& Kakumba, U. (2012). Graduate management admission test outcomes and the academic achievement: A study on Masters of Business Administration students at Makerere University, Uganda. American Journal of Business Education, 5(6), 177-183.

18. Wamala, R. \& Buyinza, M. (2013). Quality of Education Outcomes: The role of the Graduate Management Admission Test. American Journal of Business Education, 6(1), 141-147. 


\section{NOTES}

